\title{
Short-term variability of intertidal benthic community production during emersion and the implication in annual budget calculation
}

\author{
Nicolas Spilmont ${ }^{1,6, *}$, Aline Migné ${ }^{2}$, Laurent Seuront ${ }^{3,4}$, Dominique Davoult ${ }^{5}$ \\ ${ }^{1}$ UMR CNRS 8013 ELICO, Maison de la Recherche en Environnement Naturel, Université du Littoral Côte d'Opale, \\ 62930 Wimereux, France \\ ${ }^{2}$ UMR CNRS 5178 BOME, Université Pierre et Marie Curie-Paris 6, 75005 Paris, France \\ ${ }^{3}$ FRE CNRS 2816 ELICO, Station Marine de Wimereux, 62930 Wimereux, France \\ ${ }^{4}$ School of Biological Sciences, Flinders University, GPO Box 2100, Adelaide, South Australia 5001, Australia \\ ${ }^{5}$ UMR CNRS 7144 AD2M, Station Biologique, Université Pierre et Marie Curie - Paris 6, 29682 Roscoff Cedex, France \\ ${ }^{6}$ Present address: FRE CNRS 2816 ELICO, Station Marine de Wimereux, Université des Sciences et Technologies de Lille, \\ 28 av. Foch B.P. 80, 62930 Wimereux, France
}

\begin{abstract}
Short-term variability in benthic community primary production was studied during the course of emersion on a study site located in the Bay of Somme (eastern English Channel, France). Primary production was estimated at the community level through in situ measurements of carbon dioxide fluxes (infra-red analysis) in benthic chambers. Throughout the emersion period, gross community production (GCP) exhibited strong variations that were strongly correlated with natural variations in light. Light response curves explained the variations in GCP during the greater part of the emersion period, and vertical migrations of the microphytobenthos were suggested to explain the remaining variations (i.e. just before or just after immersion of the study site). A time lag was observed between the start of emersion and the maximum GCP, which was positively correlated with the time lag between emersion and local noon. The introduction of this time lag within the annual budget calculation enhanced production variability at a 2 wk time scale (i.e. tidal cycle), but light variability at the small time scale (i.e. cloudiness) remained the major factor inducing production variability. Results highlighted that omitting the time lag between emersion time and the maximum GCP within annual budget calculations led to large overestimations of annual GCP, since the annual budget for the study site was recalculated as being $67 \mathrm{~g} \mathrm{C} \mathrm{m}^{-2} \mathrm{yr}^{-1}$ compared to $110 \mathrm{~g} \mathrm{C} \mathrm{m}^{-2} \mathrm{yr}^{-1} \mathrm{when}$ the short-term variability was not taken into account.
\end{abstract}

KEY WORDS: Microphytobenthos · Vertical migration • Primary production · Intertidal environment • Temporal variability

Resale or republication not permitted without written consent of the publisher

\section{INTRODUCTION}

The microphytobenthos are an important component of estuarine primary production since they may provide as much as one-third of the total benthic primary production in some estuarine systems (Sullivan \& Moncrieff 1988). They are mainly composed of pennate diatoms, with vertical migration of cells over the course of the emersion period being widely studied (see Con- salvey et al. 2004, Underwood et al. 2005 and references therein). Other microphytobenthic taxa are also able to migrate (e.g. Euglenophyta: Kingston 2002) and surface cell microcycling has also been hypothesised, with cells of different taxa moving up and down within the biofilm (Kromkamp et al. 1998, Perkins et al. 2002, Underwood et al. 2005) to avoid exposure to inhibiting light levels, high temperature, or nutrient limitation. The rapid movements of diatoms are facili- 
tated through the production of extracellular polymeric substances (EPS; Underwood et al. 1995, Smith \& Underwood 1998). Although the pattern of migration may appear to be simple (upwards migration prior to the daytime exposure and downwards migration prior to high tide/darkness), many factors are involved in the migration process, and the ultimate driving force remains unknown (Consalvey et al. 2004). Migration rhythms are indeed partly endogenous, since they can be maintained in the laboratory in the absence of external stimuli, but are mainly controlled by tidal and light cycles (e.g. Serôdio et al. 1997, Mitbavkar \& Anil 2004). As reviewed by Consalvey et al. (2004), changes in the taxonomic composition, $\mathrm{CO}_{2}$, and/or nutrient limitation, as well as disturbance by waves, rain, or predators, are also suspected to impact migration.

Microphytobenthos migration results in large fluctuations in chlorophyll a concentration in the photic zone of the sediment (e.g. Serôdio et al. 1997, Perkins et al. 2001, Brotas et al. 2003, Tolhurst et al. 2003). This causes significant and rapid variations in the rates of primary production (Brotas et al. 2003) and has been highlighted as an important factor in the modelling of the primary production in intertidal areas (Pinckney \& Zingmark 1993, Serôdio \& Catarino 2000). Short-term variability in the primary production of microphytobenthos is related to changes in biomass, light quality and availability (Barranguet et al. 1998). These factors may interact with each other, but have different variability frequencies; it is therefore difficult to partition their impact on microphytobenthic populations.

Traditional methods used for monitoring microphytobenthic primary production are destructive as, for example core sampling. More recently, non-destructive in situ methods, such as oxygen microelectrodes (Brotas et al. 2003) and variable fluorescence measurements (Serôdio et al. 1997, Kromkamp et al. 1998, Serôdio \& Catarino 2000, Perkins et al. 2001, Brotas et al. 2003), have been used. However, scaling up these measurements to larger areas is contentious, and the validity of estimation of carbon production rates from fluorescence measurements is still being fiercely debated (e.g. Perkins et al. 2002, Brotas et al. 2003).

In the present study, we used a closed-chamber $\mathrm{CO}_{2}$ flux method for estimating short-term variations of primary production in relation to diurnal and tidal cycles over the course of emersion in the Bay of Somme (eastern English Channel). Community primary production was measured in situ in undisturbed sediment at a relatively large areal scale. The effects of short-term variability on the temporal patterns of variability of microphytobenthic primary production at larger time scales were assessed by recalculation of a previous annual primary production budget for the study site (Migné et al. 2004).

\section{MATERIALS AND METHODS}

The study was carried out in the Bay of Somme, a macrotidal estuary of the eastern English Channel (France). The experimental site, located in a muddysand facies (median grain diameter of $178 \mu \mathrm{m}$ with $2 \%$ mud; $50^{\circ} 13.554^{\prime} \mathrm{N}, 01^{\circ} 36.449^{\prime} \mathrm{E}$ ) between mean high water of neap tide and mean tide level, and subjected twice a day to flooding (semi-diurnal tidal regime), was described in Migné et al. (2004).

Community primary production during emersion was measured by monitoring the change in $\mathrm{CO}_{2}$ concentration in a benthic chamber, as described in Migné et al. (2002). A Perspex dome was fitted on a stainlesssteel ring pushed into the sediment down to about $10 \mathrm{~cm}$ and connected to a closed circuit of $\mathrm{CO}_{2}$ analysis (infra-red gas analyser LiCor Li-6251). The surface covered and the volume of trapped air were $0.126 \mathrm{~m}^{2}$ and $25 \mathrm{l}$, respectively. Each individual incubation lasted for about 15 min (with a logging frequency of $30 \mathrm{~s}$ for $\mathrm{CO}_{2}$ concentration). Incident photosynthetically active radiation (400 to $700 \mathrm{~nm}$, PAR in $\mu \mathrm{mol} \mathrm{m}{ }^{-2}$ $\mathrm{s}^{-1}$ ) and air temperature were measured inside the chamber at the sediment surface.

Four experiments were conducted to estimate shortterm variations in primary production under natural irradiance during the emersion period: 20 August 2001, 29 April 2003, 25 September 2003 and 1 August 2004. Experiments consisted in a series of incubations under ambient light in order to estimate net community production (NCP) and an incubation in darkness to estimate community respiration (CR). CR was added to measurements from individual light incubations to determine gross community production (GCP).

The relationships between GCP and light $(P / E$ curves) were described using the equation given by Webb et al. (1974):

$$
P=P_{\mathrm{m}}\left[1-\exp \left(-E / E_{\mathrm{k}}\right)\right]
$$

where $P$ is the GCP $\left(\mathrm{mg} \mathrm{C} \mathrm{m}^{-2} \mathrm{~h}^{-1}\right), P_{\mathrm{m}}$ the rate of maximal GCP, $E$ the light intensity $\left(\mu \mathrm{mol} \mathrm{m} \mathrm{m}^{-2} \mathrm{~s}^{-1}\right)$ and $E_{\mathrm{k}}$ the saturation onset parameter.

The effect of short-term variability on microphytobenthic primary production at the annual scale was assessed by recalculating the annual budget published by Migné et al. (2004). In the former, GCP was calculated as a function of PAR from exposure until flooding. In many cases (when emersion periods matched with midday), microphytobenthos was then considered to be light saturated as soon as the sediment was exposed. In the present study, short-term variability was integrated in the calculation to permit progressive decrease and increase of primary production during emersion, with respect to tides and light environment. Annual community production was estimated using 

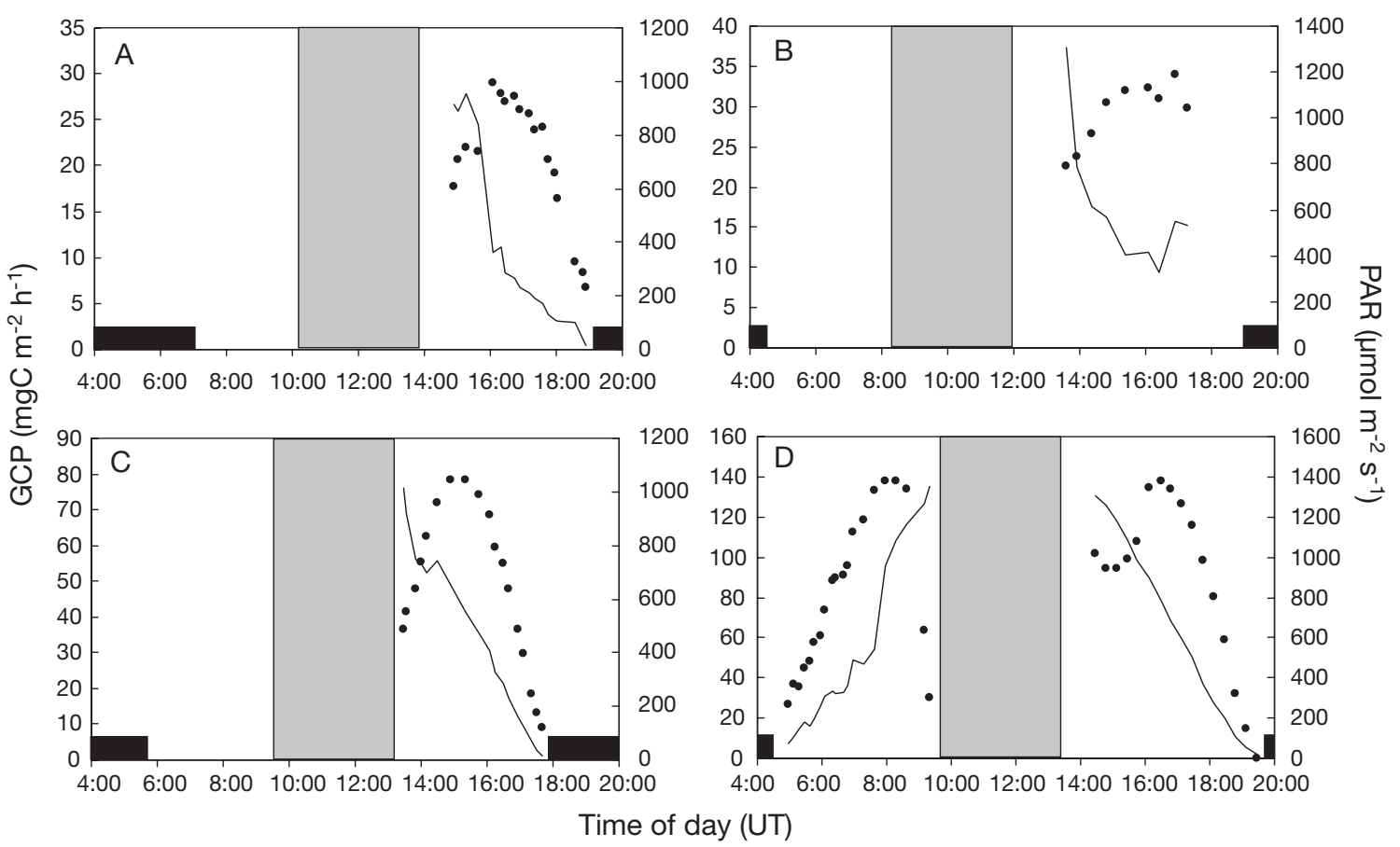

Fig. 1. Time course of gross community production (GCP, $\mathrm{mg} \mathrm{C} \mathrm{m}^{-2} \mathrm{~h}^{-1}$, dots, left axis) and irradiance $\left(\mathrm{PAR}, \mu \mathrm{mol} \mathrm{m}{ }^{-2} \mathrm{~s}^{-1}\right.$, line, right axis) recorded during experiments conducted in the Bay of Somme on (A) 20 August 2001, (B) 29 April 2003, (C) 25 September 2003 and (D) 1 August 2004. Black horizontal bars represent the night periods; shaded bars represent immersion periods

both optimal irradiance (OI: calculated after a theoretical equation and assuming no perturbation by clouds) and measured irradiance (MI: using PAR measured near the study site in intervals of 1 min), assuming that microphytobenthic production was light limited during immersion. The impact of the integration of this variability at different time scales was assessed through spectral analysis.

\section{RESULTS}

For each experiment conducted at the beginning of the emersion period (Fig. 1), the first measurements were performed when PAR was far above the saturating level $\left(E_{\mathrm{k}}\right)$ previously estimated as $112<E_{\mathrm{k}}<$ $220 \mu \mathrm{mol} \mathrm{m} \mathrm{m}^{-2} \mathrm{~s}^{-1}$ in the Bay of Somme (Migné et al. 2004). GCP nevertheless increased, reached a maximum value and then decreased together with decreasing irradiance, except on 29 April (Fig. 1B). Conversely, for the experiment conducted at the end of the emersion period (1 August 2004 a.m.), primary production rates first increased with increasing irradiance and then started to decrease when irradiance was high (Fig. 1D). Good correlations between GCP and PAR ( $>99 \%$ of the variance explained by the $P / E$ relationships obtained by fitting the model from Webb et al. 1974) were found after maximum GCP was reached, except for 29 April (Fig. 2). The rapid decrease of PAR observed in April 2003 (519 $\mu \mathrm{mol}$ $\mathrm{m}^{-2} \mathrm{~s}^{-1}$ in $20 \mathrm{~min}$, see Fig. 1B) suggested an intense and durable cloudy spell during measurements. Since microphytobenthic populations are usually not able to instantly react to sharp variations in light intensity, it was then impossible to establish the light response curve.

The time required for microphytobenthos to reach its maximum primary production rate after emersion differed between experiments; it was ca. 165 min on 20 August 2001 (Fig. 1A), 200 min on 29 April 2003 (Fig. 1B), 110 min on 25 September 2003 (Fig. 1C) and 190 min on 1 August 2004 (Fig. 1D). When measurements were conducted at the end of the emersion period (1 August 2004 a.m.), primary production started to decrease ca. $100 \mathrm{~min}$ before flooding (Fig. 1D). The time lag (TL, in min) between maximum $\mathrm{GCP}$ and emersion time ( $\mathrm{TL}_{\mathrm{GCP} / \mathrm{em}}$ ) was significantly correlated with the time lag between emersion time and local noon $\left(T L_{e m / n o o n}\right)$ :

$$
\mathrm{TL}_{\mathrm{GCP} / \mathrm{em}}=0.52\left(\mathrm{TL}_{\mathrm{em} / \mathrm{noon}}\right)+37.52
$$

where $\mathrm{n}=5, \mathrm{r}=0.943$ and $\mathrm{p}<0.01$.

This last relation was used to correct the annual budget published by Migné et al. (2004). For each day of the year $\mathrm{TL}_{\mathrm{GCP} / \mathrm{m}}$ values were calculated as a function of $\mathrm{TL}_{\mathrm{em} / \mathrm{noon}}$ GCP was then calculated using optimal 


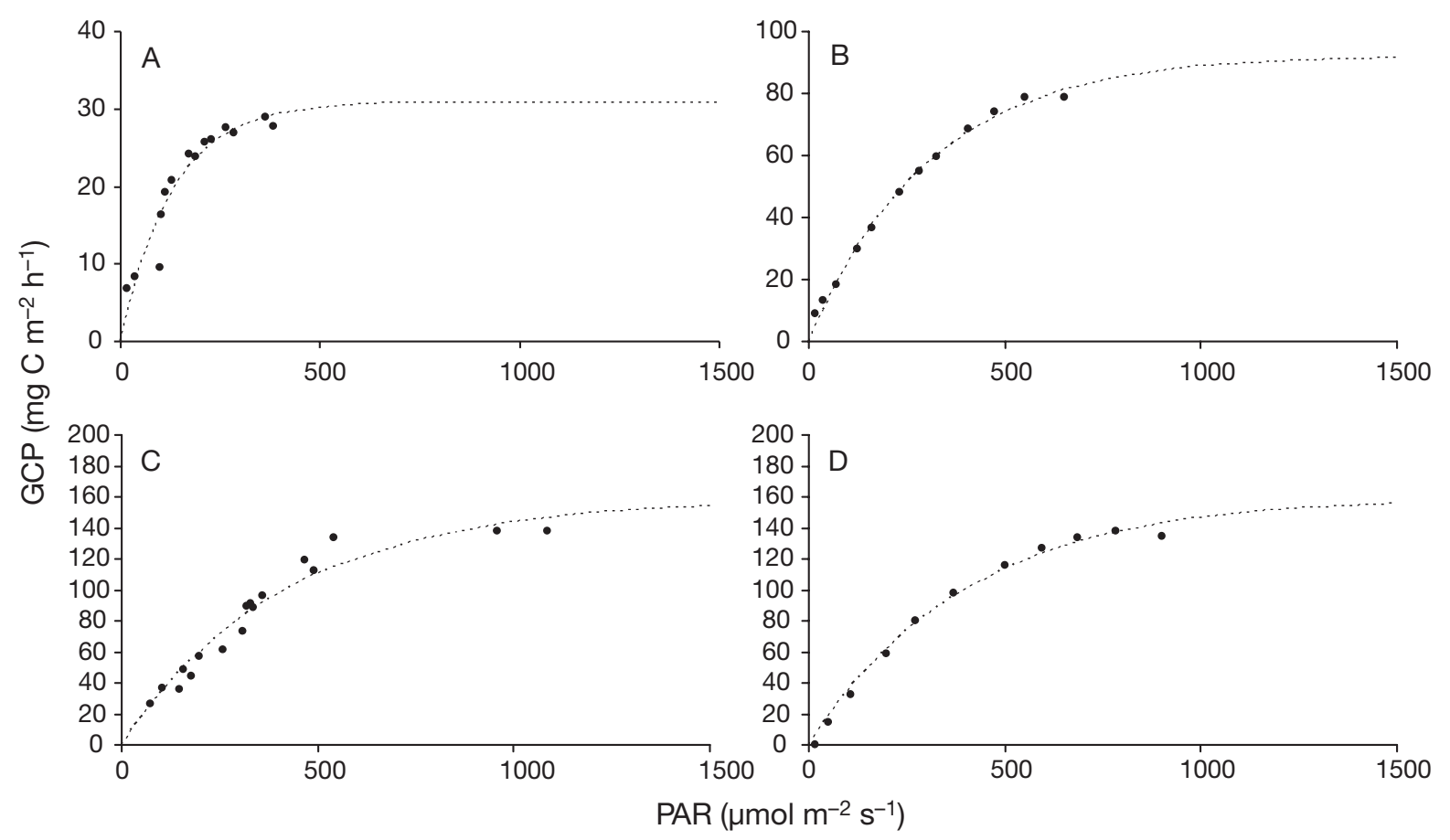

Fig. 2. Photosynthesis versus irradiance $(P / E)$ curves constructed for periods before and after maximum GCP was reached: (A) 20 August $2001\left[P=30.9\left(1-\mathrm{e}^{(-E / 131)}\right), \mathrm{n}=14, \mathrm{r}^{2}=0.990\right],(B) 25$ September $2003\left[P=92.4\left(1-\mathrm{e}^{(-E / 309)}\right), \mathrm{n}=12, \mathrm{r}^{2}=0.999\right],(\mathrm{C}) 1$ August a.m. $\left[P=158.0\left(1-\mathrm{e}^{(-E / 414)}\right), \mathrm{n}=17, \mathrm{r}^{2}=0.992\right]$ and (D) 1 August p.m. $\left[P=159.8\left(1-\mathrm{e}^{(-E / 402)}\right), \mathrm{n}=11, \mathrm{r}^{2}=0.992\right]$

and measured irradiance (OI and MI). Budget calculation was extrapolated to a whole year to enable comparisons with previously published budgets. This led to an annual GCP budget of $90 \mathrm{~g} \mathrm{C} \mathrm{m}^{-2} \mathrm{yr}^{-1}$ considering

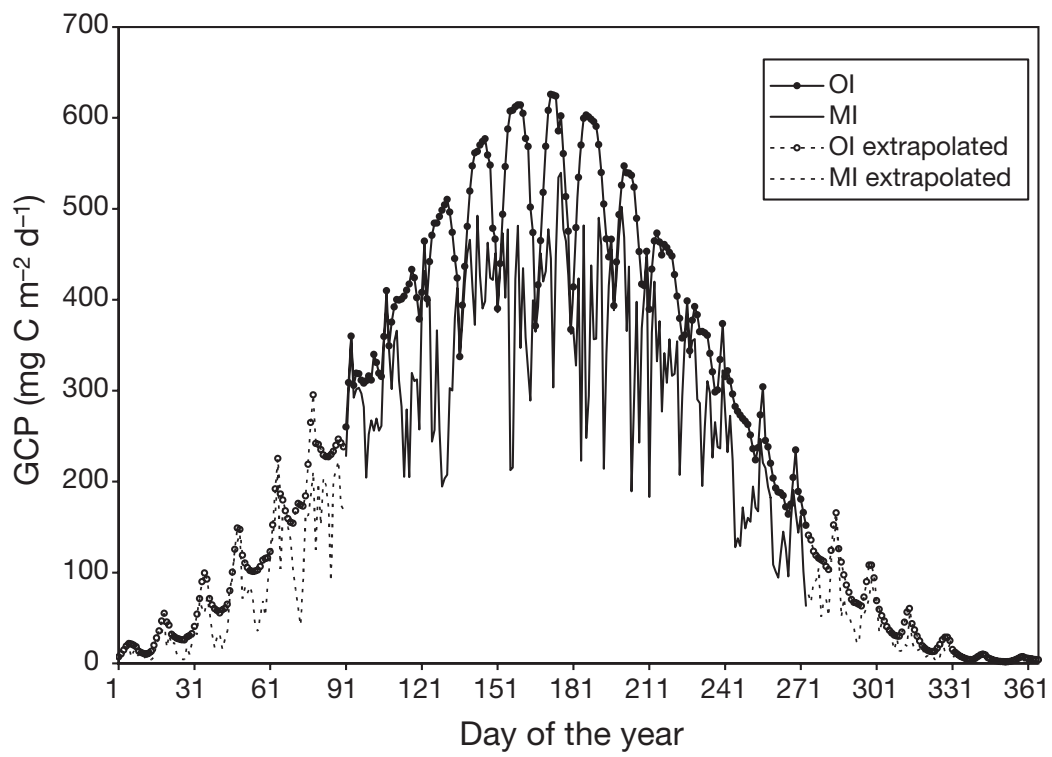

Fig. 3. Gross community production (GCP, $\mathrm{mg} \mathrm{C} \mathrm{m}^{-2} \mathrm{~h}^{-1}$ ) calculated for each day of the year, according to optimal or measured irradiances (OI, MI, respectively), after introducing in the calculation a variable time lag between maximum GCP and emersion time (dashed lines correspond to the period when data were extrapolated)
OI and of $67 \mathrm{~g} \mathrm{C} \mathrm{m}^{-2} \mathrm{yr}^{-1}$ considering MI (Fig. 3). In contrast, these budgets were, respectively, 147 and $110 \mathrm{~g} \mathrm{C} \mathrm{m}^{-2} \mathrm{yr}^{-1}$ when short-term variability was not taken into account (Migné et al. 2004). This variability per se thus accounted for a decrease of $39 \%$ in the annual budget. Migné et al. (2004) concluded a net heterotrophic budget for the study site (considering an annual community respiration of $188 \mathrm{~g} \mathrm{C} \mathrm{m}^{-2} \mathrm{yr}^{-1}$ ). This result is not questioned, but reinforced, since the budget would be -98 and $-121 \mathrm{~g} \mathrm{C}$ $\mathrm{m}^{-2} \mathrm{yr}^{-1}$ using optimal and measured PAR, respectively.

The highest relative differences induced by this correction in budget calculation were observed in winter and fall (Fig. 4). On each day of the year, GCP was overestimated for at least 37.5 min (when emersion matched with local noon; see Eq. 2) in the previous budget. This duration represents a greater proportion of the total day length in fall and winter (e.g. $490 \mathrm{~min}$ day length on 21 December) than in spring and summer (e.g. 970 min day length on 21 June). The correction impact was low during winter and fall 
neap tides, when emersion matched with a nonsaturating PAR period at the study site. Conversely, neap tide periods correspond to the highest discrepancies at the end of spring/beginning of summer, when only 1 of the 2 emersion periods matching with local noon occurred during daytime. The strongest fluctuations once every $2 \mathrm{wk}$, estimated as a decrease in daily production of $21 \%$ in summer (June) and an increase of $22 \%$ in autumn (October) by Migné et al. (2004), were refined here as being 27 and $37 \%$, respectively (Fig. 3).

The induced variability every $14 \mathrm{~d}$ can be better illustrated through Fourier power spectral analysis (Fig. 5), in which the variability (i.e. the variance) of a given pattern was decomposed as a function of the time scale. The Fourier power spectra calculated with and without consideration of the time lag between maximum GCP and emersion time for optimal and measured light conditions indicated that when optimal irradiance was considered (Fig. 5A) the spectral density $E(f)$ (i.e. the variance) was lower when this variable time lag was considered, except for frequencies $f$ bounded between 0.0618 and $0.0743 \mathrm{~d}^{-1}$. This corresponded to a mean period (1/f) of $14.8 \mathrm{~d}$ ( $2 \mathrm{wk}$ variability). The spectra obtained when measured irradiance was considered (Fig. 5B) showed the higher variability induced by cloudiness; the 2 curves have similar patterns, but that calculated in the previous budget remains clearly higher. Light availability thus remained the major factor inducing variability, but, when the budget was corrected, the relative importance of the 2 wk variability on the annual variability increased by about 3 -fold when optimal irradiance was

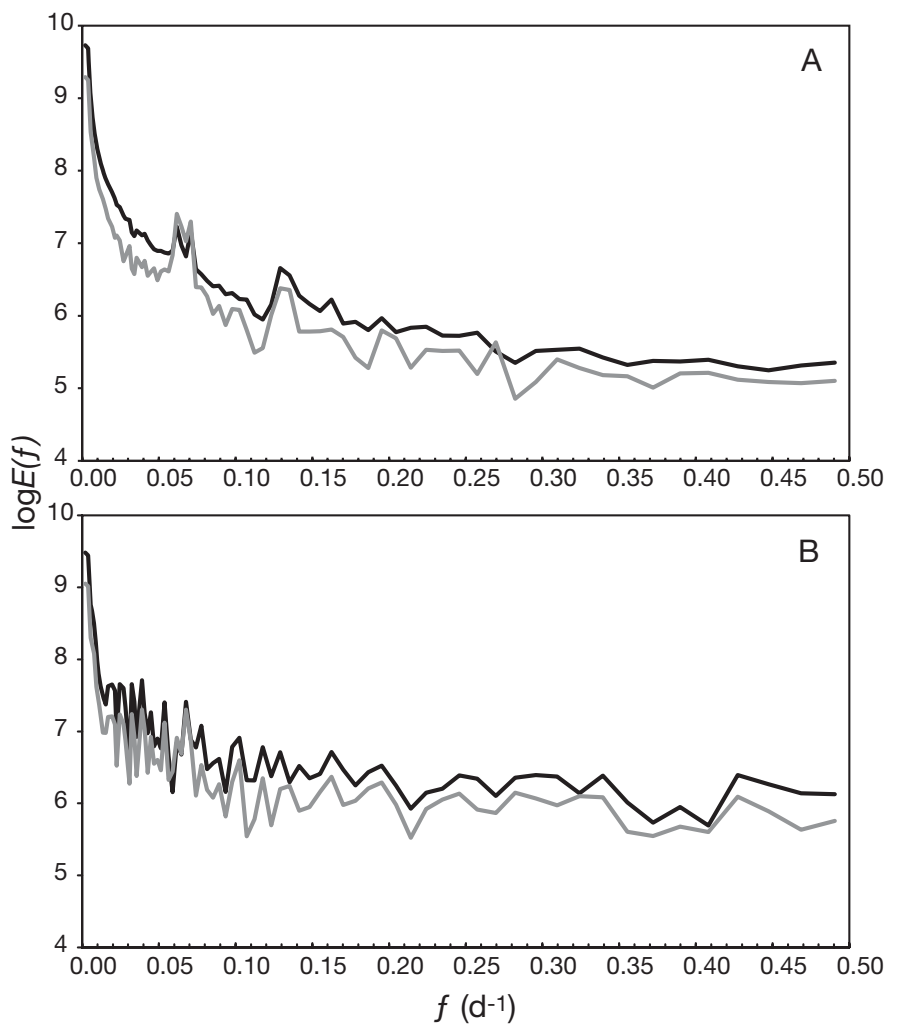

Fig. 5. Fourier power spectra $E(f)$ of the GCP calculated for time series considering optimal irradiance (A) and measured irradiance (B), with the variable time lag between maximum GCP and emersion time included (grey line) or not (black line)

considered (from 0.18 to $0.62 \%$ ) and by about 2 -fold when measured irradiance was considered (from 0.28 to $0.58 \%$ ).

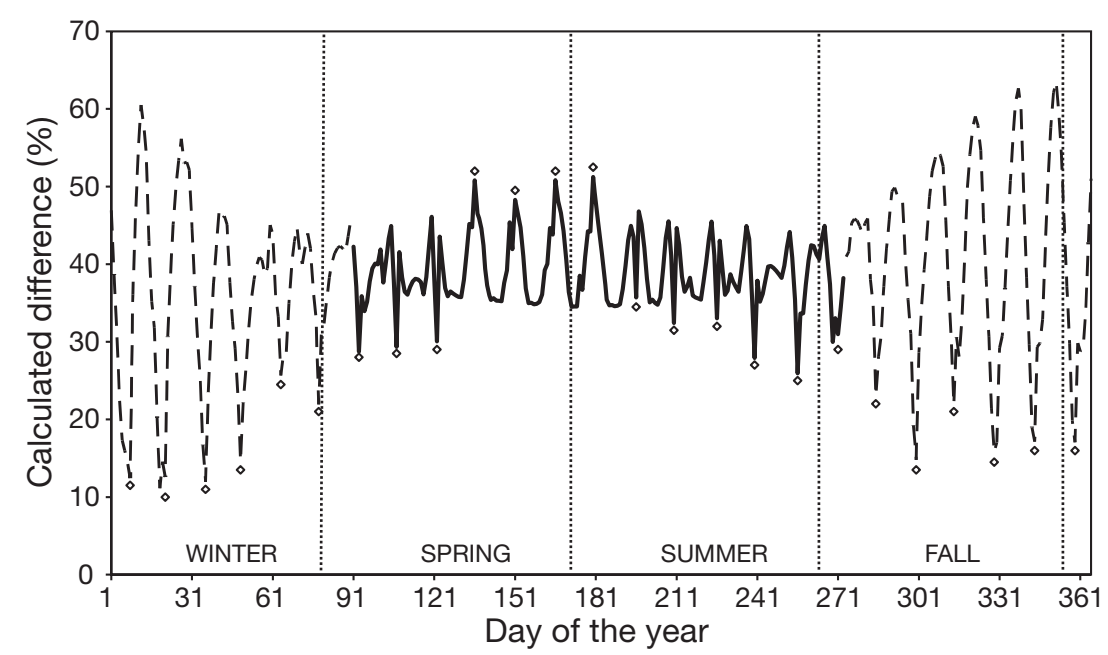

Fig. 4. Difference between daily GCPs estimated with and without consideration of a variable time lag between maximum GCP and emersion time (present study and Migné et al. 2004, respectively), expressed as the percentage of the previously published budget for each day of the year. Rhomb indicates neap tide, and the dashed lines correspond to the period when data were extrapolated

\section{DISCUSSION}

In the present study we used a non-destructive technique to monitor short-term variations in benthic primary production in situ. Previously, Brotas et al. (2003) and Underwood et al. (2005) studied the variability in microphytobenthic primary productivity over a diurnal cycle using nondestructive in situ methods (microelectrodes and PAM fluorescence). As pointed out by these authors, in situ measurements are needed, since it is very difficult to simulate variability in the factors controlling primary production in the laboratory, especially their short-term variability. Furthermore, the method we used allowed us to carry out relatively short incuba- 
tions (about $15 \mathrm{~min}$ ), compared to other incubation techniques such as ${ }^{14} \mathrm{C}$ uptake and oxygen exchange rates, and was adequate to calculate carbon budgets, since measurements were performed at the community level.

Despite these different methods and units, the variations in GCP in the course of emersion measured in the present study seemed to be consistent with those reported in laboratories and in situ studies (we used a photosynthetic quotient of 1.2 to convert $\mathrm{O}_{2}$ fluxes into $\mathrm{CO}_{2}$ fluxes for comparisons). A strong hour-to-hour GCP variability was indeed previously observed: from about 0 to $150 \mathrm{mg} \mathrm{C} \mathrm{m}{ }^{-2} \mathrm{~h}^{-1}$ by Serôdio \& Catarino (2000) and from 87 to $243 \mathrm{mg} \mathrm{C} \mathrm{m}^{-2} \mathrm{~h}^{-1}$ by Brotas et al. (2003). The observed pattern in the short-term variability of primary production may be ascribed to many factors, i.e. light availability, temperature, desiccation, $\mathrm{CO}_{2}$, or nutrient limitation. Temperature has been shown to have an important effect on photosynthetic rates under saturating irradiance at the study site (Migné et al. 2004), but the weak variations in temperature under saturating irradiance measured in the present study $\left(<1^{\circ} \mathrm{C}\right)$ were not able to change drastically the primary production. Light availability inducing migration of the motile fraction of the microphytobenthos can thus mainly be considered to be involved in the observed short-term variability. Indeed, it has been shown that GCP was closely correlated to irradiance during sunrise and sunset (Fig. 2), and, above all, a positive correlation between the time lag between maximum GCP and emersion time and the time lag between emersion time and local noon was highlighted (Eq. 2). Previous studies already showed that maximum biomass and production seemed to occur when low tide matched with local noon (Pinckney \& Zingmark 1991, Mitbavkar \& Anil 2004). This may be explained by an increase in the depth of the photic zone; microalgae in the upper sediment are then in a favourable light environment without the need to migrate and additional light is provided to buried microalgae. The increase in production as a response to a decrease in irradiance on each experimental date after the immersion period (Fig. 1) could be interpreted as negative phototaxis (downward vertical migration of microphytobenthos under supersaturating irradiances). We can argue that this pattern was most likely due to a tidal effect (downward migration of the cells to protect from resuspension) since Eq. (2) does not validate a phototaxis hypothesis (GCP reached its maximum more quickly when emersion matches with local noon, i.e. with high irradiance).

Nevertheless, Eq. (2) was calculated using a dataset in which the timing of immersion was always approximately at the same time, i.e. when immersion matched with local noon (Fig. 1), and we then implicitly made the assumption that the correlation was as significant when immersion and noon did not occur together. Furthermore, morning and afternoon data were gathered to calculate the relationship, even if emersion was prior to the light period for the morning data set, whereas emersion was during the light period and hence just prior to the maximum GCP and around the time of maximum PAR for the afternoon cases. Even making these assumptions, our results agreed with previous studies, but it appeared that a more accurate relationship could be obtained by treating morning and afternoon cases separately, more data for the morning then being needed.

Short-term variability in chl a biomass and primary production seems to be time, taxon and location specific. Observed maximal chl a biomass in the surface sediment after the beginning of exposure is highly variable (ca. $90 \mathrm{~min}$, Tolhurst et al. 2003; ca. $300 \mathrm{~min}$, Perkins et al. 2001) and appeared to decrease ca. 70 min before flooding (Perkins et al. 2001). Furthermore, Perkins et al. (2002) and Underwood et al. (2005) have shown that significant changes may take place in the species composition of the upper microphytobenthos at a short time scale (minutes). Even when chl a biomass was not monitored during the experiments, variation in biomass in the photic zone on 1 August 2004 (Fig. 1D) was evidenced by large shifts between GCP just before emersion (30 $\mathrm{mg} \mathrm{C} \mathrm{m}^{-2} \mathrm{~h}^{-1}$ ) and GCP just after emersion (102 mg $\mathrm{C} \mathrm{m}^{-2} \mathrm{~h}^{-1}$ ). Furthermore, seasonal and inter-annual variations in specific composition of the microphytobenthos (not measured) may also be involved in the measured GCP variations. This was, however, not confirmed by Migné et al. (2004), who did not observe variations in biomass or primary production between years in their pluri-annual set of data.

The introduction of the variable time lag between maximum GCP and local noon into the budget calculation enhanced variability at a temporal scale of once every 2 wk. Serôdio \& Catarino (2000) also showed that the production variability every $14 \mathrm{~d}$ increased when migratory rhythms were considered, and it was much higher than the variability obtained in the present study. This can be related to the strong seasonal pattern obtained in our study through the introduction of sinusoidal curves in our model (see Fig. 3), whereas the data of Serôdio \& Catarino did not exhibit such a seasonal pattern (see their Fig. 10). In our study, the variability for a period of $177 \mathrm{~d}$, which corresponds to about half the year, was about $20 \%$.

Despite the great decrease in the primary production budget calculation due to the introduction of the variable time lag, the annual GCP calculated $\left(90 \mathrm{~g} \mathrm{C} \mathrm{m}^{-2}\right.$ $\mathrm{yr}^{-1}$ with optimal irradiance and $67 \mathrm{~g} \mathrm{C} \mathrm{m}^{-2} \mathrm{~h}^{-1}$ with measured irradiance) was still in the range of values 
given by Cahoon (1999) for temperate intertidal areas $\left(111 \pm 99 \mathrm{~g} \mathrm{C} \mathrm{m}^{-2} \mathrm{yr}^{-1}\right)$. The new annual NCP calculated (-98 and $-121 \mathrm{~g} \mathrm{C} \mathrm{m}^{-2} \mathrm{yr}^{-1}$ using optimal and measured PAR, respectively) reinforced the conclusion that the study site was a net heterotrophic environment, as generally expected for estuarine areas. While temporal variations in primary production in connection with the physical and the biological environment are now better understood, respiration estimations still remain a critical issue. In the present study, annual respiration was underestimated for at least 2 main reasons: we considered that respiration was not light nor tide dependant (i.e. constant throughout the day and night and throughout emersion and immersion), while some studies have shown that this is generally not the case. Respiration rates in the light may be higher than those in the dark (Epping \& Jørgensen 1996), and respiration is expected to increase during immersion (Gribsholt \& Kristensen 2003).

It still appears to be critical to develop production models that consider the variability of both production and respiration rates at several time scales, ranging from hourly to seasonal, particularly when results are extrapolated to larger spatial scales. The improvement of these calculations will ultimately result in more accurate estimates of the primary production of the coastal benthic ecosystem. This first step is needed before assessing how increasing human perturbations will affect the overall metabolic potential of coastal ecosystems, e.g. through changes in ecosystem functioning and sea level rise.

Acknowledgements. This work was supported by the Programme National sur l'Environnement Côtier (PNEC Manche Orientale). We are grateful to D. Menu for maintaining the chamber. We also thank 3 anonymous referees and $\mathrm{T}$. Meziane for helpful comments on the manuscript.

\section{LITERATURE CITED}

Barranguet C, Kromkamp J, Peene J (1998) Factors controlling primary production and photosynthetic characteristics of intertidal microphytobenthos. Mar Ecol Prog Ser 173:117-126

Brotas V, Risgaard-Petersen N, Serôdio J, Ottensen L, Dalsgaard T, Ribeiro L (2003) In situ measurements of photosynthetic activity and respiration of intertidal benthic microalgal communities undergoing vertical migration. Ophelia 57:13-26

Cahoon LB (1999) The role of benthic microalgae in neritic ecosystems. Oceanogr Mar Biol Annu Rev 37:47-86

Consalvey M, Paterson DM, Underwood GJC (2004) The ups and downs of life in a benthic biofilm: migration of benthic diatoms. Diatom Res 19:181-202

Epping EHG, Jørgensen BB (1996) Light-enhanced oxygen respiration in benthic phototrophic communities. Mar Ecol Prog Ser 139:193-203

Editorial responsibility: Victor de Jonge (Contributing Editor), Haren, The Netherlands
Gribsholt B, Kristensen E (2003) Benthic metabolism and sulfur cycling along an inundation gradient in a tidal Spartina anglica salt marsh. Limnol Oceanogr 48:2151-2162

Kingston MB (2002) Effect of subsurface nutrient supplies on the vertical migration of Euglena proxima (Euglenophyta). J Phycol 38:872-880

Kromkamp J, Barranguet C, Peene J (1998) Determination of microphytobenthos PSII quantum efficiency and photosynthetic activity by means of variable chlorophyll fluorescence. Mar Ecol Prog Ser 162:45-55

Migné A, Davoult D, Spilmont N, Menu D, Boucher G, Gattuso JP, Rybarczyk H (2002) A closed-chamber $\mathrm{CO}_{2}$-flux method for estimating intertidal primary production and respiration under emersed conditions. Mar Biol 140: 865-869

Migné A, Spilmont N, Davoult D (2004) In situ measurements of benthic primary production during emersion: seasonal variations and annual potential production in the Bay of Somme (eastern English Channel, France). Cont Shelf Res 24:1437-1449

Mitbavkar S, Anil AC (2004) Vertical migratory rhythms of benthic diatoms in a tropical intertidal sand flat: influence of irradiance and tides. Mar Biol 145:9-20

Perkins RG, Underwood GJC, Brotas V, Snow GC, Jesus B, Ribeiro L (2001) Responses of microphytobenthos to light: primary production and carbohydrate allocation over an emersion period. Mar Ecol Prog Ser 223:101-112

Perkins RG, Oxborough K, Hanlon ARM, Underwood GJC, Baker NR (2002) Can chlorophyll fluorescence be used to estimate the rate of photosynthetic electron transport within microphytobenthic biofilms? Mar Ecol Prog Ser 228:47-56

Pinckney J, Zingmark RG (1991) Effects of tidal stage and sun angles on intertidal benthic microalgal productivity. Mar Ecol Prog Ser 76:81-89

Pinckney J, Zingmark RG (1993) Modeling the annual production of intertidal benthic microalgae in estuarine ecosystems. J Phycol 29:396-407

Serôdio J, Catarino F (2000) Modelling the primary productivity of intertidal microphytobenthos: time scales of variability and effects of migratory rhythms. Mar Ecol Prog Ser 192:13-30

Serôdio J, Marques da Silva J, Catarino F (1997) Nondestructive tracing of migratory rhythms of intertidal benthic microalgae using in vivo chlorophyll a fluorescence. J Phycol 33:542-553

Smith DJ, Underwood GJC (1998) Exopolymer production by intertidal epipelic diatoms. Limnol Oceanogr 43: 1578-1591

Sullivan MJ, Moncrieff CA (1988) Primary production of edaphic algal communities in a Mississipi salt marsh. J Phycol 24:49-58

Tolhurst TJ, Jesus B, Brotas V, Paterson DM (2003) Diatom migration and sediment armouring - an example from the Tagus Estuary, Portugal. Hydrobiologia 503:183-193

Underwood GJC, Paterson DM, Parkes RJ (1995) The measurement of microbial carbohydrate exopolymers in intertidal sediments. Limnol Oceanogr 40:1243-1253

Underwood GJC, Perkins RG, Consalvey MC, Hanlon ARM, Oxborough K, Baker NR, Paterson DM (2005) Patterns in microphytobenthic primary productivity: species-specific variation in migratory rhythms and photosynthetic efficiency in mixed-species biofilms. Limnol Oceanogr 50: 755-767

Webb WL, Newton M, Starr D (1974) Carbon dioxide exchange of Abrus rubra: a mathematical model. Oecologia 17:281-291

Submitted: June 1, 2005; Accepted: July 20, 2006

Proofs received from author(s): February 12, 2007 